\title{
Desenvolvimento de plantas de cobertura e produtividade da soja conforme atributos físicos em solo compactado
}

\author{
Romano R. Valicheski ${ }^{1}$, Fernando Grossklaus ${ }^{2}$, Sidinei L. K. Stürmer ${ }^{1}$, \\ Antonio L. Tramontin ${ }^{3}$ \& Elena S. A. S. Baade ${ }^{1}$
}

\begin{abstract}
RESUMO
Com a intensa utilização de tecnologias voltadas à mecanização das operações agrícolas, a compactação do solo é um fator que tem limitado a produtividade. Para atenuar este problema, o uso de plantas de cobertura do solo é frequentemente recomendado. Com o objetivo de avaliar o efeito da compactação nas propriedades físicas do solo, no desenvolvimento de plantas de cobertura e na produtividade da soja, conduziu-se um experimento no delineamento em blocos casualizados no esquema fatorial $2 \times 5$, sendo duas espécies de plantas de cobertura (aveia preta - Avena strigosa e nabo forrageiro - Raphanus sativus) e cinco níveis de compactação (0, 2, 4, 6 e 8 passadas de trator com 5,0 Mg na superfície do solo), com quatro repetições. Intensidades de tráfego superiores a 2 passadas de trator alteram a densidade do solo, a porosidade total e a resistência mecânica à penetração, na camada de 0-0,10 m, e reduzem, de forma linear, a altura e a produção de matéria seca da parte aérea das plantas de cobertura. O cultivo da aveia preta ou nabo forrageiro antecedendo a soja, associado ao uso de sulcadores na operação de semeadura da soja minimiza os efeitos da compactação do solo, possibilitando obter-se produtividades superiores a $3,5 \mathrm{t} \mathrm{ha}^{-1}$.
\end{abstract}

Palavras-chave: densidade do solo, resistência mecânica à penetração, adubação verde, produção de soja

\section{Growth of cover crops and soybean yield according to physical attributes in compacted soil}

\begin{abstract}
With the intense use of technologies geared toward the mechanization of agricultural operations, soil compaction is a factor limiting productivity. To mitigate this problem, the use of ground cover crops is frequently recommended. With the objective to determine the effect of compaction on the soil physical properties, an experiment was carried out using randomized block design in a 2 × 5 factorial scheme. Two cover crop species (black oat - Avena strigosa and forage radish - Raphanus sativus), five levels of compaction $(0,2,4,6$ and 8 tractor passes with $5.0 \mathrm{Mg}$ on the soil surface), with four repetitions were studied. Traffic intensities greater than 2 tractor passes change soil density, total porosity, and mechanical penetration resistance at a depth of $0-0,10 \mathrm{~m}$, as well as linearly reduce the height and dry matter production of the above-ground parts of the cover crops. The cultivation of black oat or forage radish preceding the soybeans, associated with the use of a furrower during soybean sowing minimizes the effects of soil compaction, permitting to obtain productivity greater than $3,5 \mathrm{t} \mathrm{ha}^{-1}$.
\end{abstract}

Key words: soil density, mechanical penetration resistance, green manure, soybean production

\footnotetext{
IFC-Rio do Sul. Estrada do Redentor, 5665, Canta Galo, CEP 89160-000, Rio do Sul, SC. Fone: (47) 3531-3700. E-mail: romano@ifc-riodosul.edu.br sidineileandro@gmail.com; elenasetelich1@zipmail.com.br

Graduando, IFC-Rio do Sul. Fone (47) 9106-3948. E-mail: fgnando@hotmail.com

Mestrando, Manejo do solo/CAV-UDESC, Av Luiz Camões, 2090, Bairro Conta Dinheiro, CEP 88520-000, Lages, SC. Fone: (47) $8822-1201$. E-mail: toninhotramontin@yahoo.com.br
} 


\section{INTRODUÇÃO}

Várias pesquisas realizadas no País apontam para alterações consideráveis nas propriedades físicas do solo, causadas pelo tráfego intenso de máquinas e implementos de preparo do solo. Tais alterações indicam não apenas decréscimo na porosidade do solo mas também aumento significativo na densidade do solo, ocasionando um impedimento físico ao desenvolvimento do sistema radicular das plantas (Freddi et al., 2007; Bergamim et al., 2010; Ribeiro et al., 2010).

Dentre as consequências diretas da compactação do solo pode se citar o aumento da resistência mecânica do solo à penetração das raízes (Beutler \& Centurion, 2003; Collares et al., 2008; Ralisch et al., 2008), a redução da porosidade, da continuidade dos poros, da permeabilidade e da aeração do solo (Soane \& Ouwerkerk, 1994).

Como os macroporos têm papel fundamental na movimentação de gases no solo, são também chamados porosidade de aeração. Os efeitos da compactação na aeração do solo podem, portanto, ser avaliados através da análise da ocorrência de macroporos, de tal forma que valores críticos para este fator frequentemente são estabelecidos na literatura. Em geral, considera-se que $0,25 \mathrm{~m}^{3} \mathrm{~m}^{-3}$ representa boa porosidade de aeração enquanto valores abaixo de $0,10 \mathrm{~m}^{3} \mathrm{~m}^{-3}$ representam deficiência de aeração (Ros et al., 1997).

Devido à sua praticidade e rapidez na determinação, a resistência mecânica do solo à penetração (RP), tem sido uma medida amplamente utilizada para avaliar o estado de compactação do solo. No entanto, esta é variável conforme o conteúdo de água em que se encontra o solo no momento de sua avaliação. Segundo Smith et al. (1997) este atributo apresenta forte relação com o crescimento radicular e é muito influenciado pelo teor de umidade e pela condição estrutural do solo, o que dificulta a obtenção de valores limitantes em relação à produção e ao desenvolvimento das culturas.

Por estar diretamente relacionada ao crescimento das plantas, a RP tem sido um dos atributos físicos priorizados em trabalhos que estudam a compactação do solo (Carvalho et al., 2006; Beutler et al., 2007; Ralisch et al., 2008). Valores críticos de RP variam de 1,5 a 4,0 MPa, conforme o tipo de solo e a espécie vegetal sendo, em geral, o valor de 2,0 MPa aceito como impeditivo ao crescimento radicular (Tormena et al., 1998).

Resultados têm comprovado que as espécies apresentam diferentes capacidades de crescimento radicular em camadas compactadas (Jimenez et al., 2008). Assim, a resistência mecânica à penetração que ocasionou a redução de $50 \%$ no crescimento radicular, foi de 0,69 MPa para a soja (Rosolem et al., 1994a) e de 1,42 MPa para o milho (Rosolem et al., 1994b). Para a cultura do feijão Guimarães et al. (2002) observaram que o aumento da compactação do solo afetou negativamente o desenvolvimento do sistema radicular e da parte aérea do feijoeiro, efeito este mais expressivo a partir de densidades do solo de 1,2 $\mathrm{Mg} \mathrm{m}^{-3}$. Além disso, também podem existir diferenças dentro da mesma espécie, conforme constatado por Beulter et al. (2006), para diferentes materiais genéticos de soja, ao observarem redução na produtividade, quando o solo apresenta resistência mecânica à penetração superior a 2,24 MPa.
Além do processo mecânico de romper camadas compactadas do solo com uso de escarificadores e subsoladores, a utilização de espécies de plantas de cobertura, sobretudo com a utilização da rotação de culturas com espécies vegetais com sistema radicular vigoroso, faz-se conveniente visto que, além da proteção da superfície do solo com a presença de resíduos vegetais, as raízes dessas espécies vão-se decompor, deixando canais que proporcionarão o aumento do movimento de água e a difusão de gases (Müller et al., 2001). Além do efeito do sistema radicular, conforme Braida et al. (2006), o acúmulo de matéria orgânica no solo, proporcionado por diferentes formas de manejo, aumenta sua umidade crítica para a compactação, tornando-o mais resistente. Conforme os autores, a manutenção da palhada na superfície do solo dissipa, até $30 \%$, a energia de compactação à qual o solo é submetido.

No cultivo da soja (praticamente todo mecanizado), frequentemente são relatados problemas de compactação nas camadas superficial/subsuperficial do solo, resultando em decréscimo na produtividade. Para esta cultura, segundo Silva et al. (2006), há redução no crescimento da parte aérea em densidade superior a $1,40 \mathrm{Mg} \mathrm{m}^{-3}$.

Realizou-se este trabalho com o objetivo de avaliar o efeito da compactação nos atributos físicos do solo, no desenvolvimento vegetativo de espécies de plantas de cobertura e na produtividade da soja, tal como identificar qual das espécies de adubo verde testadas possui maior potencial para mitigar os efeitos da compactação do solo.

\section{Material E MÉTODOS}

O experimento foi montado em junho de 2009 em uma área agricultável do Instituto Federal Catarinense - Campus Rio do Sul, SC. A análise química da amostra de solo coletada na profundidade de $0,0-0,20 \mathrm{~m}$ revelou $\mathrm{pH}$ em água de 6,3, teores de $\mathrm{Ca}^{+2}, \mathrm{Mg}^{+2}$ e $\mathrm{Al}^{+3}$ de, respectivamente, 5,1; 3,2 e 0,0 $\mathrm{cmol}_{\mathrm{c}} \mathrm{dm}^{-3}, 2,0 \mathrm{mg} \mathrm{dm}^{-3}$ de Pe $52 \mathrm{mg} \mathrm{dm}^{-3} \mathrm{de} \mathrm{K}^{+}$, saturação por bases de $77 \%$ e teor de matéria orgânica de $31 \mathrm{~g} \mathrm{dm}^{-3}$. Quanto à composição granulométrica o solo possui $21 \%$ de areia, $58 \%$ de silte e $21 \%$ de argila, sendo classificado pelo diagrama textural como franco siltoso. Antes da implantação do experimento realizou-se uma subsolagem até $25 \mathrm{~cm}$ de profundidade fazendose, em seguida, uma gradagem leve para eliminar os torrões.

$\mathrm{O}$ delineamento experimental adotado foi o de blocos casualizados no esquema fatorial 2 × 5 , ou seja, duas espécies de plantas de cobertura (aveia preta - Avena strigosa e nabo forrageiro - Raphanus sativus) e cinco níveis de compactação (obtidos com 0, 2, 4, 6 e 8 passadas de trator com massa de 5,0 $\mathrm{Mg}$ em toda a área superficial de cada parcela experimental), com quatro repetições. Depois de demarcar as parcelas experimentais $(4,2 \times 5,0 \mathrm{~m})$, implementaram-se os níveis de compactação $36 \mathrm{~h}$ após precipitação pluviométrica de $32 \mathrm{~mm}$ (solo com umidade próximo à capacidade de campo). Para isto, utilizou-se um trator Massey Ferguson modelo 292 - 4 x 4, acoplado de pá carregadeira e massa total ajustada a 5,0 Mg conforme pesagem, munido de pneus dianteiros e traseiros com largura de $0,38 \mathrm{~m}$, calibrados com 24 e $19 \mathrm{Lb} \mathrm{pol}^{2}$, respectivamente. Trafegou-se passando-se lado a lado com 
rodado em toda a área superficial de cada parcela experimental; em seguida foram coletadas, nas profundidades $0,0-0,10 \mathrm{~m}$, 0,10-0,20 m e 0,20-0,30 m, amostras indeformadas de solo em anel volumétrico $\left(65 \mathrm{~cm}^{3}\right)$, para determinação da densidade do solo $(\rho s)$ e da porosidade total (PT). A PT foi determinada a partir dos valores de $\rho$ s e da densidade de partículas $(\rho)$, para a qual se adotou o valor médio de $2,65 \mathrm{Mg} \mathrm{m}^{-3}$ conforme EMBRAPA (1997). Também foi definida a resistência mecânica do solo à penetração até $0,30 \mathrm{~m}$ de profundidade, utilizando-se um penetrômetro de haste metálica marca Falker, modelo Penetrolog $1020^{\circ}$, que permite registrar valores de RP a cada 0,01 m (manuseado sempre pelo mesmo operador). Neste momento coletaram-se amostras deformadas de solo nas camadas de $0-0,10 \mathrm{~m}, 0,10-0,20 \mathrm{~m}$ e $0,20-0,30 \mathrm{~m}$ com quatro repetições, as quais foram secadas em estufa $\left(65-70{ }^{\circ} \mathrm{C}\right)$, determinando-se então a umidade gravimétrica (EMBRAPA, 1997) e se obtendo, para essas profundidades, valores médios de 252,325 e $378 \mathrm{~g} \mathrm{~kg}^{-1}$ respectivamente.

Em 20/05/2009 foi realizada a semeadura das espécies de plantas de cobertura de solo utilizando-se, para a aveia preta, $80 \mathrm{~kg} \mathrm{ha}^{-1}$ de sementes, e para o nabo forrageiro, $25 \mathrm{~kg} \mathrm{ha}^{-1}$ conforme EPAGRI (1993). Após a semeadura (realizada a lanço) efetuou-se manualmente com enxada, um leve revolvimento do solo ( 1 a $2 \mathrm{~cm}$ de profundidade) para cobrir as sementes. Da semeadura até a época da avaliação das variáveis biométricas das plantas não se realizou controle fitossanitário para doenças, pragas e plantas daninhas.

Quando as plantas estavam em plena floração determinouse a altura com uma fita métrica; em seguida, foi lançado ao acaso um quadrado com área interna de $1 \mathrm{~m}^{2}$ sobre cada parcela experimental cortando-se, rente ao solo, todas as plantas inseridas nesta área. O material vegetal coletado em cada parcela foi acondicionado em saco de papel, determinando-se então a biomassa fresca produzida; prosseguindo, essas amostras foram submetidas à secagem em estufa com circulação forçada de $\operatorname{ar}\left(65-70^{\circ} \mathrm{C}\right)$ até atingirem peso constante determinando-se então, em balança de precisão, a massa de matéria seca.

A soja (cultivar CD236 RR) foi semeada em 20/11/2009 no espaçamento de $0,50 \mathrm{~m}$ entre linhas e população de 260.000 plantas ha-1. Utilizou-se uma semeadora-adubadora Seed Max 2126, na qual se regularam os sulcadores para operar a $0,07 \mathrm{~m}$ de profundidade. Como adubação de base foram utilizados 230 $\mathrm{kg} \mathrm{ha}^{-1}$ do fertilizante químico formulado 05-20-10. O controle de plantas daninhas foi realizado via aplicação de herbicida à base de glifosato. Para controle de pragas aplicou-se, via pulverização, aos 30 e 50 dias após a semeadura, inseticida à base de deltametrina enquanto para o controle de doenças (principalmente ferrugem asiática) foi aplicado, aos 70, 80, 95 e
105 dias após a germinação, fungicida à base de tebuconazol com dosagem de $0,35 \mathrm{~L} \mathrm{ha}^{-1}$ de produto comercial por pulverização. Quando a soja atingiu o ponto de colheita (152 dias após a semeadura), foram coletadas, ao acaso, cinco plantas em cada parcela experimental, utilizadas para avaliação da altura, número de galhos, número de vagens e peso de 1000 sementes. A colheita para avaliação da produtividade foi realizada em 10/04/2010. O arranquio das plantas foi efetuado manualmente e a trilha com uma batedeira de cereais estacionária tratorizada, marca Vencedora Maqtron modelo B 380. Após ajustar a umidade dos grãos para 13\%, determinou-se a massa total de grãos estimando-se, então a produtividade em $\mathrm{kg} \mathrm{ha}^{-1}$.

Após tabulação dos dados realizou-se a análise de variância utilizando-se o programa SAS-Statistical Analyses Sistem (SAS Institute, 2002) para verificar se houve ou não efeitos dos tratamentos a nível de 0,05 de probabilidade. Os tratamentos qualitativos foram comparados por meio do teste de Tukey ( $\mathrm{p}$ $<0,05)$; já os quantitativos, por modelo de regressão linear ou polinomial, conforme cada caso.

\section{RESULTADOS E DISCUSSÃO}

Quanto aos atributos físicos do solo observou-se, logo após a implementação dos níveis de compactação na camada de 0,0 $0,10 \mathrm{~m}$, efeito altamente significativo para densidade do solo ( $\rho s)$, porosidade total (PT) e resistência mecânica do solo a penetração (RP) e, para as camadas de 0,10-0,20 e 0,20-0,30 m, constatou-se efeito significativo apenas para a variável RP (Tabela 1).

Para densidade do solo (Figura 1A) na camada de 0,0-0,10 $\mathrm{m}$, duas passadas de trator na superfície do solo resultaram em um incremento significativo nos valores de $\rho$ s, passando de 1,21 para $1,34 \mathrm{Mg} \mathrm{m}^{-3}$. Para intensidades maiores de tráfego (4, 6 e 8 passadas), a despeito de ser observado incremento nos valores de densidade até 6 passadas de trator, não houve diferença significativa entre tais tratamentos. Quanto às camadas mais profundas, não se constatou diferença estatística entre os tratamentos, obtendo-se valor médio de $1,26 \mathrm{Mg} \mathrm{m}^{-3}$ para a camada de $0,10-0,20 \mathrm{~m}$ e de $1,22 \mathrm{Mg} \mathrm{m}^{-3}$ para a camada 0,20-0,30 m (Figura 1A). Freddi et al. (2007) encontraram, trabalhando em um Latossolo Vermelho distrófico típico, textura média, submetido a diferentes intensidades de tráfego, resultados de densidade do solo similares aos obtidos neste trabalho.

$\mathrm{Na}$ camada de 0,0-0,10 m o incremento expressivo nos valores de densidade do solo após as duas primeiras passadas de trator é resultante, possivelmente, da ruptura dos agregados

Tabela 1. Valores de F e nível de significância para as diversas fontes de variação, bem como o coeficiente de variação para densidade do solo $(\rho s)$, porosidade total $(\mathrm{PT})$ e resistência mecânica do solo à penetração (RP) nas camadas de 0$0,10,0,10-0,20$ e $0,20-0,30 \mathrm{~m}$

\begin{tabular}{|c|c|c|c|c|c|c|c|c|c|}
\hline \multirow{2}{*}{$\begin{array}{c}\text { Camada } \\
\text { F.V. }\end{array}$} & \multicolumn{3}{|c|}{$0-0,10 \mathrm{~m}$} & \multicolumn{3}{|c|}{$0,10-0,20 \mathrm{~m}$} & \multicolumn{3}{|c|}{$0,20-0,30 \mathrm{~m}$} \\
\hline & $\rho s^{3}$ & $\mathrm{PT}^{4}$ & $\mathbf{R P}^{5}$ & $\rho s$ & PT & $\mathbf{R P}$ & $\rho s$ & PT & $\mathbf{R P}$ \\
\hline Bloco & $4,94^{*}$ & $5,22^{*}$ & $6,72^{\star \star}$ & $3,76^{\star}$ & $3,74^{\star}$ & $0,62^{\mathrm{ns}}$ & $2,38^{\mathrm{ns}}$ & $2,83^{\text {ns }}$ & $0,48^{\text {ns }}$ \\
\hline Compactação & $13,8^{\star \star}$ & 13,97 ** & $38,08^{* *}$ & $1,66^{\text {ns }}$ & $1,54^{\mathrm{ns}}$ & $3,34^{*}$ & $2,58^{\text {ns }}$ & $2,43^{\text {ns }}$ & $5,82^{*}$ \\
\hline C.V. $(\%)^{2}$ & 2,82 & 2,82 & 15,31 & 4,26 & 3,8 & 30,6 & 5,28 & 4,41 & 15,1 \\
\hline
\end{tabular}


A.
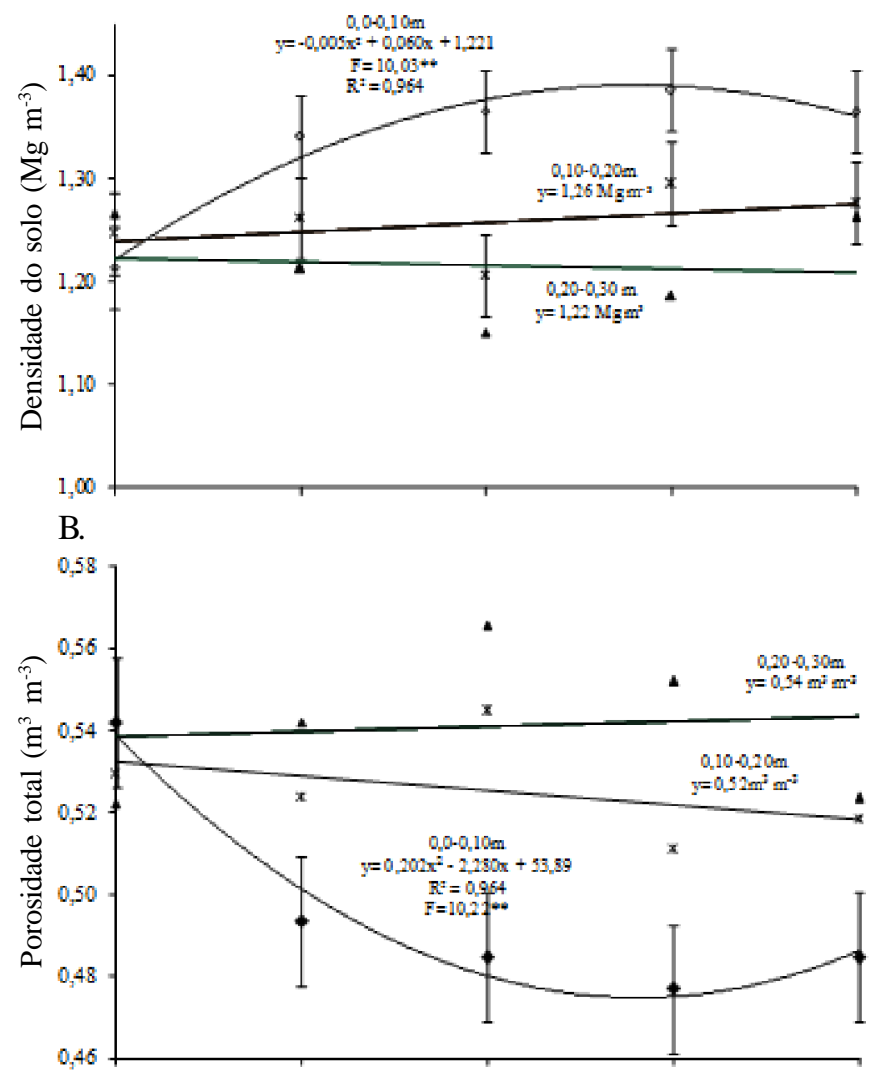

C.

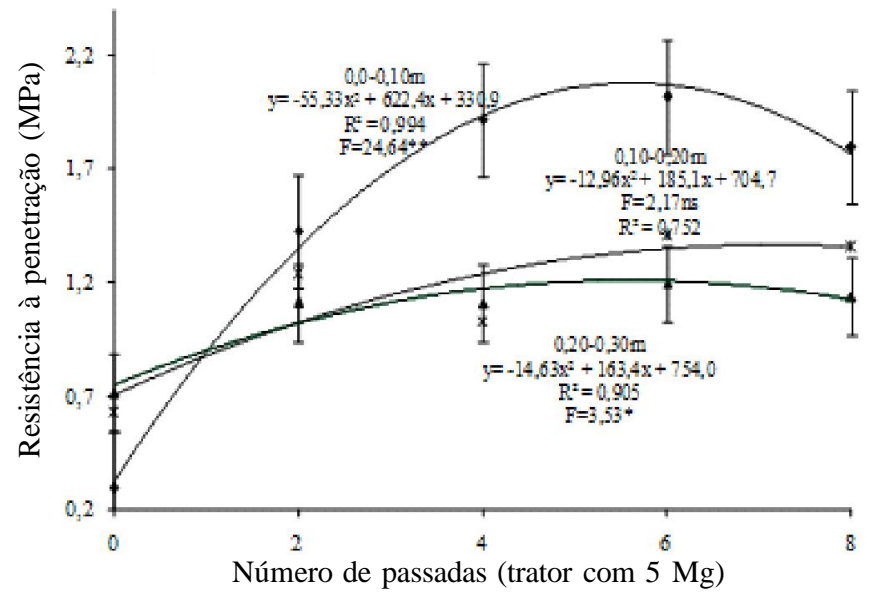

As barras verticais referem-se ao erro-padrão da média e a não-sobreposição dentro da mesma camada indica diferença significativa entre os tratamentos

Figura 1. Densidade do solo (A), porosidade total (B) e resistência do solo a penetração $(C)$ nas camadas de 0-0,10, 0,10-0,20 e 0,20-0,30 m em função dos níveis de compactação obtidos com diferentes intensidades de tráfego

do solo favorecendo, sem dúvida, a aproximação das partículas e, em conseqüência, a compactação do solo. Conforme Smith et al. (1997), o tráfego de máquinas na superfície do solo com umidade excessiva, ocasiona quebra dos agregados do solo, originando uma organização melhor das partículas do solo o que, em contrapartida, eleva sua densidade e resistência mecânica a penetração.

Similar ao ocorrido à densidade do solo, para a porosidade total também houve uma redução significativa logo após as duas primeiras passadas de trator na camada $0,0-0,10 \mathrm{~m}$ (Figura 1B).
Nesta camada é provável que a redução da PT seja resultante do aumento da densidade do solo. Para Tavares Filho et al. (1999), a estrutura do solo é modificada em função da compactação e os macroagregados do solo, os primeiros a serem destruídos. Para esta variável não foi observada, nas camadas mais profundas $(0,10-0,20$ e 0,20-0,30 m) diferença entre as intensidades de tráfego testadas obtendo-se, respectivamente, valores médios de $0,52 \mathrm{e} 0,54 \mathrm{~m}^{3} \mathrm{~m}^{-3}$ para porosidade total.

Os resultados obtidos para densidade do solo e porosidade total mostram que as alterações mais expressivas dos atributos físicos do solo ocorrem na camada mais superficial do solo e logo após as primeiras passadas de trator devendo-se evitar, então, transitar com máquinas agrícolas, estando o solo nas condições de umidade em que foram implementados os níveis de compactação.

Quanto aos valores de resistência mecânica do solo a penetração, na camada de 0,0-0,10 m, a expressiva alteração da densidade do solo e da porosidade total, ocasionada logo após as duas primeiras passadas de trator, resultou também em um significativo incremento nos valores de RP, que passou de 0,29 para 1,43 MPa (Figura 1C). Nas camadas mais profundas $(0,10-0,20$ e $0,20-0,30 \mathrm{~m})$ este efeito foi menos pronunciado observando-se efeito significativo dos níveis de tráfego apenas após seis passadas de trator, quando se obtiveram os valores máximos próximos a 1,20 MPa. Na camada mais superficial (0$0,10 \mathrm{~m}$ ), além da intensidade de tráfego que ocasionou diferentes níveis de compactação do solo, outro fator que possivelmente contribuiu para obtenção de valores mais elevados de RP, foi a menor umidade do solo $\left(252 \mathrm{~g} \mathrm{~kg}^{-1}\right)$, quando comparado com as camadas mais profundas $\left(325 \mathrm{~g} \mathrm{~kg}^{-1}\right.$ para 0,10-20 $\mathrm{m} \mathrm{e} 378 \mathrm{~g} \mathrm{~kg}^{-1}$ para 0,20-0,30 m).

Segundo Beutler \& Centurion (2003), a resistência do solo a penetração é variável conforme o teor de umidade em que se encontra o solo no momento de sua avaliação; assim, em solos semelhantes um teor maior de água leva à menor resistência a penetração.

Conforme os dados obtidos, constata-se que, para a camada mais superficial do solo, quatro passadas de trator são suficientes para atingir valores considerados restritivos ao desenvolvimento radicular. Para Tormena et al. (1998) valores críticos de RPvariam de 1,5 a 4,0 MPa sendo, de modo geral, o valor de 2,0 MPa aceito como impeditivo ao crescimento radicular. Rosolem et al. (1994b), constataram que a RP de 1,42 MPa ocasionou redução de 50\% no crescimento radicular do milho.

Na Tabela 2 estão sendo apresentados os valores de F e coeficiente de variação para as variáveis relacionadas ao

Tabela 2. Valores de F e nível de significância para as diversas fontes de variação, bem como o coeficiente de variação para as variáveis relacionadas ao desenvolvimento da parte aérea das plantas de cobertura

\begin{tabular}{|c|c|c|c|}
\hline \multirow{2}{*}{ F.V. ${ }^{1}$} & \multirow{2}{*}{$\begin{array}{l}\text { Altura } \\
\text { (cm) }\end{array}$} & \multicolumn{2}{|c|}{ Biomassa } \\
\hline & & Fresca & Seca \\
\hline A.V. ${ }^{2}$ & $18,14^{\star \star}$ & $14,89 * *$ & $76,75^{\star *}$ \\
\hline $\mathrm{C.}^{3}$ & 15,27 ** & $32,53^{\star *}$ & 25,4 ** \\
\hline A.V.X C. & $14,63^{\star \star}$ & $0,96^{\mathrm{ns}}$ & $4,24^{\star}$ \\
\hline C.V. $(\%)^{4}$ & 14,5 & 13,5 & 16,7 \\
\hline
\end{tabular}
*significativo; **altamente significativo 
desenvolvimento da parte aérea das plantas de cobertura. Para os fatores espécie de adubação verde e compactação do solo, observou-se efeito altamente significativo $(\mathrm{p}<0,01)$ em todas as variáveis analisadas. Quanto ao efeito da interação espécie de adubo verde x compactação do solo, este foi altamente significativo para a variável altura das plantas e significativo $(\mathrm{p}<0,05)$ para biomassa seca da parte aérea.

A aveia preta, independente do nível de compactação do solo, apresentou maior produção de fitomassa quando comparado com o nabo forrageiro (Tabela 3). Para as variáveis biomassa fresca e biomassa seca da parte aérea, esta gramínea foi superior ao nabo forrageiro em 30,5 e 53,8\%, respectivamente. Quanto aos dados de produção de biomassa seca produzida na parte aérea, o valor obtido para a aveia preta foi de 3,997 $\mathrm{Mg} \mathrm{ha}^{-1}$, similar ao relatado por Silva et al. (2007) que obtiveram produção média de $3,6 \mathrm{Mg} \mathrm{ha}^{-1}$. Já para o nabo forrageiro a quantidade de matéria seca obtida neste trabalho foi inferior à dos valores apresentados por Forsthofer et al. (2006) e Silva et al. (2007), que relatam produção de biomassa seca entre 4,7 a 5,7 Mg ha- ${ }^{-1}$. Como o nabo forrageiro é uma planta que possui sistema radicular tuberoso, a elevada resistência do solo a penetração, principalmente nos níveis mais intenso de tráfego (Figura 1C), restringiu o desenvolvimento das raízes resultando, assim, em menor volume de solo explorado e, consequentemente, em menor quantidade de nutrientes absorvida e menor desenvolvimento da parte aérea. Já a aveia preta, por ter sistema radicular fasciculado (que possibilitou o desenvolvimento das raízes em pequenas fissuras, conforme observação visual), explorou maior volume de solo resultando, então, em maior desenvolvimento da parte aérea.

Tabela 3. Altura das plantas, biomassa fresca e seca obtidas para o nabo forrageiro e para a aveia preta cultivados em um solo submetido a diferentes intensidades de tráfego

\begin{tabular}{lccc}
\hline \multirow{2}{*}{ Adubação verde } & Altura & \multicolumn{2}{c}{ Biomassa $\left(\right.$ Mg ha $\left.^{-1}\right)$} \\
\cline { 3 - 4 } & (cm) & Fresca & Seca \\
Aveia Preta & $84,9 \mathrm{~b}$ & $25,87 \mathrm{a}$ & $3,997 \mathrm{a}$ \\
Nabo Forrageiro & $93,5 \mathrm{a}$ & $17,97 \mathrm{~b}$ & $1,846 \mathrm{~b}$ \\
\hline
\end{tabular}

Médias seguidas da mesma letra não diferem entre si pelo teste $\mathrm{F}$ a $5 \%$

Independente da espécie de planta de cobertura utilizada nos tratamentos com 0 e 2 passadas de trator, a produção de biomassa fresca pela parte aérea foi estatisticamente superior à dos demais tratamentos (Figura 2A). Para esta variável obtevese, nas parcelas sem tráfego, valor médio de $39,6 \mathrm{Mg} \mathrm{ha}^{-1}$. Esses dados estão de acordo com os relatados por Bordin et al. (2008), que cultivaram vegetação espontânea (gramíneas), guandu (Cajanus cajan) e milheto (Panissetum americanum) em solo com e sem escarificação, observando maior produção de matéria verde para todas as plantas cultivadas no solo escarificado. Para esta variável e a despeito de não ser observada diferença significativa para os níveis de tráfego de 0 e 2 passadas, há uma redução linear na quantidade de fitomassa produzida pela parte aérea das plantas de cobertura com o incremento do tráfego sobre a superfície do solo. Conforme o modelo obtido, cada passada de trator sobre a superfície do solo ocasiona redução de 4,03 $\mathrm{Mg} \mathrm{ha}^{-1}$ na quantidade total de fitomassa produzida (Figura 2A).

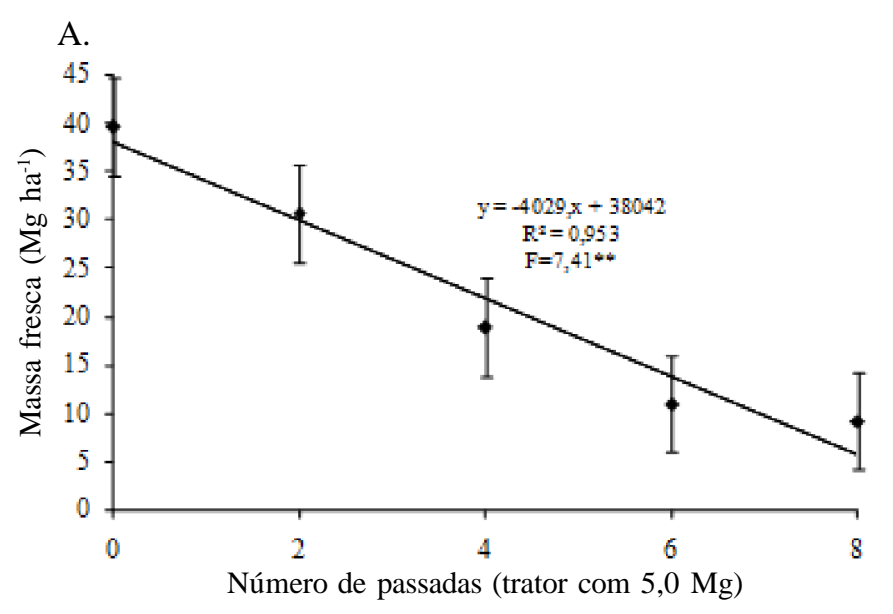

B.

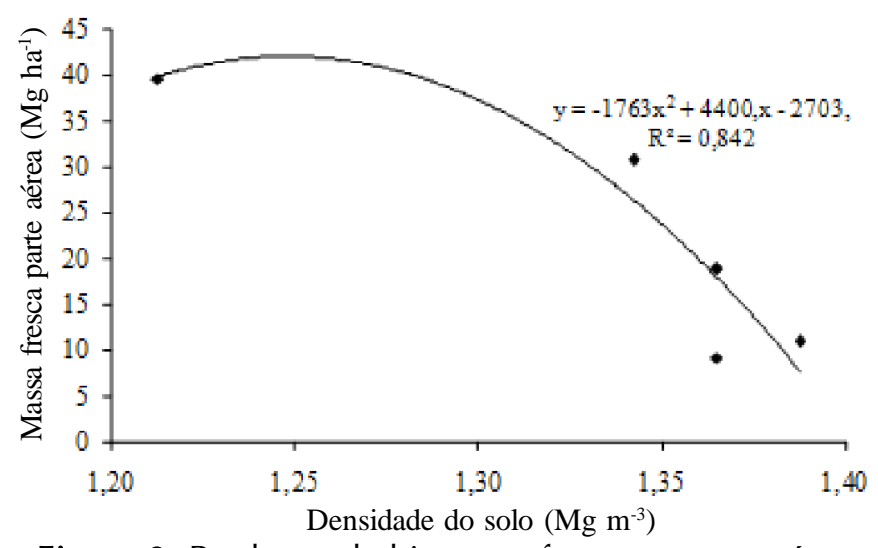

Figura 2. Produção de biomassa fresca na parte aérea das plantas de cobertura em função dos níveis de tráfego (A) e da densidade do solo (B) nas condições em que foi desenvolvido o experimento

Ao se plotar os valores médios de biomassa fresca com os de densidade do solo para as diferentes intensidades de tráfego no início da implantação do experimento, observa-se, pelo modelo, que uma leve compactação do solo resulta em condições mais favoráveis ao desenvolvimento das plantas obtendo-se valor máximo de 41,71 $\mathrm{Mg} \mathrm{ha}^{-1}$ de fitomasssa com densidade de 1,24 $\mathrm{Mg} \mathrm{m}^{-3}$ (Figura 2B). Resultados similares a estes são relatados por Silva et al. (2006) para soja, milho, algodão e Bracharia brizantha, e por Guimarães et al. (2002), para o feijão, os quais obtiveram maior crescimento da parte aérea estando o solo com densidade próximo a $1,20 \mathrm{Mg} \mathrm{m}^{-3}$ (densidade similar à obtida nas parcelas sem tráfego). Conforme os resultados obtidos observa-se que uma baixa intensidade de tráfego sobre a superfície do solo, por ocasionar uma leve compactação, melhora o contato solo/raiz, favorecendo a absorção de água e nutrientes e, consequentemente, aumenta a produção de fitomassa pela parte aérea. Para os níveis mais elevados de trafegabilidade (4, 6 e 8 passadas) o menor desenvolvimento da parte aérea das plantas está associado, provavelmente, à reduzida macroporosidade e à elevada resistência do solo à penetração, na camada de 0,0-0,10 m (Figura 1B e 1C). Conforme Dias Júnior (2000), a compactação 
afeta primeiro os macroporos os quais, por sofrerem expressiva deformação, podem transformar-se em microporos. Conforme este autor, a compactação do solo, apesar de alterar a macroporosidade pode, embora não necessariamente, afetar a porosidade total. Como nos níveis mais intensos de tráfego ocorreu uma redução significativa da porosidade total (Figura 1B), supõe-se que a quantidade de macroporos foi severamente reduzida o que, associado aos elevados valores de RP (Figura 1C), resultou em restrição ao desenvolvimento das raízes, tanto quanto na produção de fitomassa, pela parte aérea.

Quanto ao efeito da interação níveis de trafego x plantas de cobertura para a variável altura das plantas (Figura 3A) observa-se, para o nabo forrageiro, uma redução linear com o incremento no número de passadas de trator, enquanto para a aveia preta este efeito foi quadrático. A maior altura das plantas de nabo forrageiro com baixa intensidade de tráfego $(0$ e 2 passadas de trator) está associada, possivelmente, ao melhor desenvolvimento do sistema radicular das plantas nessas condições pois, devido a esta espécie possuir sistema radicular tuberoso associado ao fato de, após a semeadura, ser realizada apenas uma leve escarificação do solo para enterrar as sementes, nos níveis de maior compactação do solo (conforme constatação visual), o sistema radicular não conseguiu romper

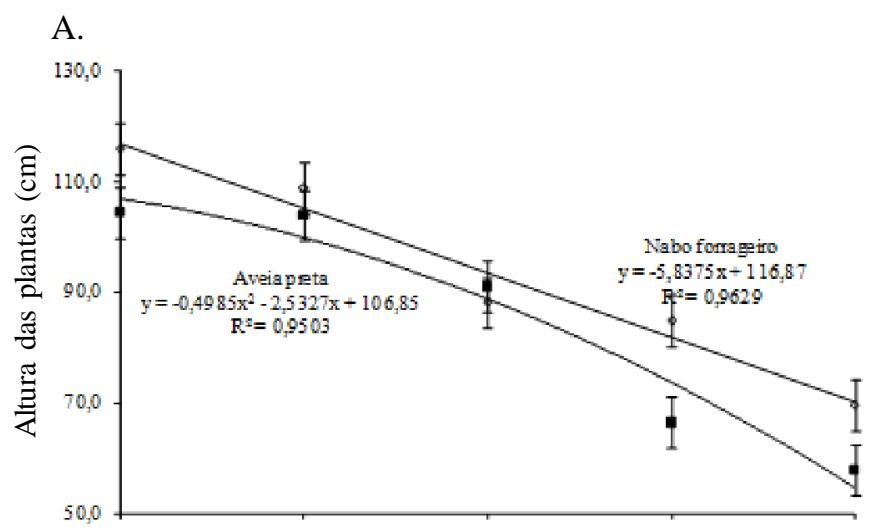

B.

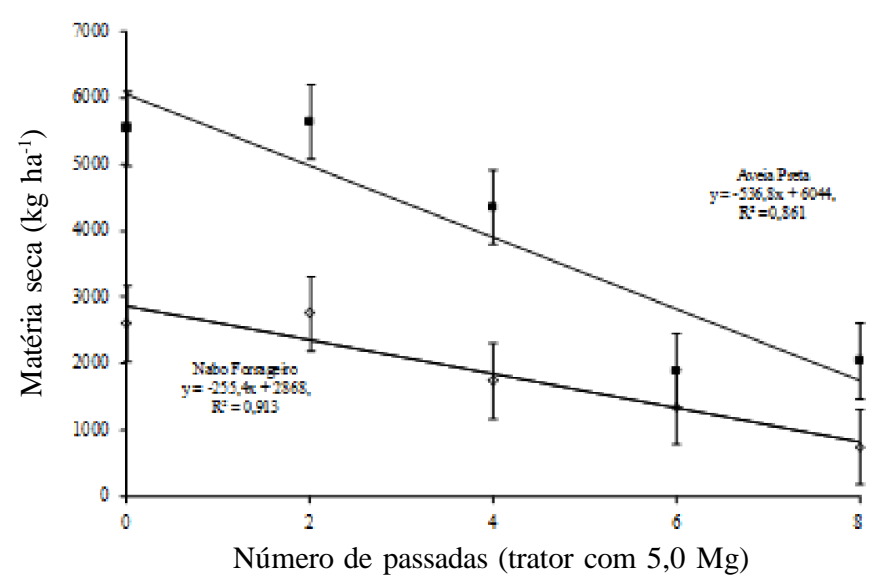

Figura 3. Efeito da interação níveis de tráfego x planta de cobertura para altura das plantas (A) e produção de matéria seca na parte aérea (B) para o nabo forrageiro e aveia preta. A não transposição das barras verticais entre pontos da mesma planta de cobertura indica que há diferença estatística a camada compactada do solo limitando, assim, o desenvolvimento das plantas. Para a aveia preta e a despeito de se ter obtido resultado similar ao do nabo forrageiro, há uma redução acentuada na altura das plantas em intensidade de tráfego superior a 4 passadas de trator, indicando que a mesma, apesar de possuir elevada produção de matéria seca na parte aérea (Figura 3B), é afetada de forma mais expressiva pelos níveis de compactação testados. Tanto para aveia preta quanto para o nabo forrageiro, o maior desenvolvimento das plantas nas menores intensidades de tráfego ( 0 e 2 passadas) é resultante de um sistema radicular mais desenvolvido, possibilitando maior profundidade de exploração do solo e, em consequência, melhor absorção de água e nutrientes.

Para a variável produção de biomassa seca o efeito da interação níveis de tráfego x plantas de cobertura é apresentado na Figura 3B. Com o incremento nos níveis de tráfego na superfície do solo há, em ambas as espécies, uma redução linear na quantidade de biomassa seca produzida. Conforme os modelos obtidos cada passada de trator sobre o solo reduz $536,8 \mathrm{~kg} \mathrm{ha}^{-1}$ de matéria seca produzida pela aveia preta e 255,4 $\mathrm{kg} \mathrm{ha}^{-1}$ pelo nabo forrageiro.

Em todos os níveis de compactação a aveia preta produziu praticamente o dobro de matéria seca que o nabo forrageiro demonstrando, daí, ter grande potencial de utilização como planta de cobertura do solo quando se objetiva a produção de palhada haja vista que, mesmo em condições pouco propícias para seu desenvolvimento, como nos níveis mais elevados de trafegabilidade (6 e 8 passadas de trator), foi possível obter-se aproximadamente $3.000 \mathrm{~kg} \mathrm{ha}^{-1}$ de biomassa seca. Os dados obtidos para esta variável discordam com os apresentados por Müller et al. (2001), os quais obtiveram maior produção de matéria seca para o nabo forrageiro quando comparado com a aveia preta. Conforme os autores, este resultado foi relacionado à melhor distribuição radicular em profundidade no solo quando comparado com a aveia preta, conferindo-lhe melhores condições de crescimento.

Na Figura 4 está sendo mostrado o efeito da resistência do solo à penetração sobre a produção de matéria seca pela parte aérea do nabo forrageiro e da aveia preta. Para as duas espécies nos níveis mais baixos de compactação, o incremento da RP

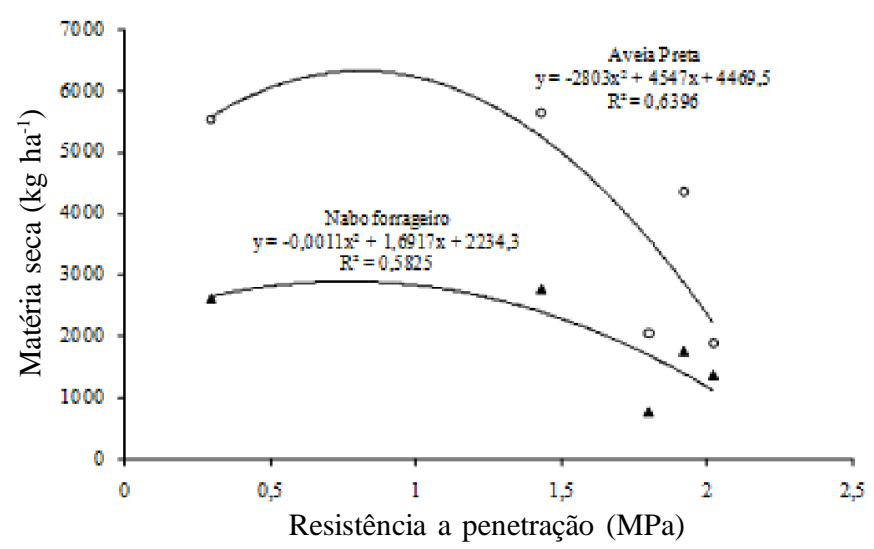

Figura 4. Produção de matéria seca na parte aérea produzida pela parte aérea do nabo forrageiro da aveia preta em função da resistência à penetração na camada de 0,0 $0,10 \mathrm{~m}$ 
resultou em um aumento na produção de biomassa seca na parte aérea que, possivelmente está associado ao melhor contato solo/raiz, resultando em condições mais favoráveis à absorção de água e nutrientes (Soane \& Ouwerkerk, 1994). Conforme os modelos obtidos para ambas as espécie, o valor de 0,80 MPa de RP foi que proporcionou máxima produção de biomassa seca na parte aérea obtendo-se $2.887 \mathrm{~kg} \mathrm{ha}^{-1}$ para o nabo forrageiro e $6.320 \mathrm{~kg} \mathrm{ha}^{-1}$ para a aveia preta. Adespeito de a aveia preta produzir praticamente o dobro que o nabo forrageiro (fato que demonstra o potencial de utilização desta gramínea em lavouras que adotam o sistema de plantio direto), observa-se que, quando os valores de RP são superiores a 1,4MPa, há redução acentuada na quantidade de biomassa seca produzida pela parte aérea demonstrando, assim, maior susceptibilidade da mesma aos níveis mais elevados de compactação; já para o nabo forrageiro e apesar da menor quantidade de matéria seca produzida, esta redução após o ponto de máxima é menos acentuada, sugerindo maior tolerância às condições restritivas impostas pela compactação do solo.

Conforme Tormena et al. (1998), a resistência do solo à penetração é um atributo que afeta diretamente o desenvolvimento do sistema radicular das planta; em contrapartida, a absorção de água e nutrientes. Para as espécies testadas esta limitação ocorreu, possivelmente, nos níveis de tráfego superiores a duas passadas de trator quando se observaram valores de RP superiores a 1,5 MPa.

Quanto aos componentes de produção e produtividade da soja cultivada após as espécies de adubo verde (Tabela 4), observa-se que não houve efeito significativo das plantas de cobertura, dos níveis de compactação nem da interação dos fatores.

Tabela 4. Valores de F e nível de significância para as diversas fontes de variação, bem como o coeficiente de variação para altura das plantas (AP), número de galhos (NG), número de vagens (NV), massa de mil sementes (MMS) e produtividade (Prod.)

\begin{tabular}{lccccc}
\hline \multicolumn{1}{c}{ FV $^{(\mathbf{1})}$} & AP & NG & NV & MMS & Prod. \\
A.V. ${ }^{(2)}$ & $1,08^{\mathrm{ns}}$ & $0,05^{\mathrm{ns}}$ & $0,40^{\mathrm{ns}}$ & $0,87^{\mathrm{ns}}$ & $1,07^{\mathrm{ns}}$ \\
C. ${ }^{(3)}$ & $0,83^{\mathrm{ns}}$ & $1,34^{\mathrm{ns}}$ & $2,42^{\mathrm{ns}}$ & $0,78^{\mathrm{ns}}$ & $0,58^{\mathrm{ns}}$ \\
A.V.X C. & $1,11^{\mathrm{ns}}$ & $0,92^{\mathrm{ns}}$ & $0,43^{\mathrm{ns}}$ & $1,20^{\mathrm{ns}}$ & $1,38^{\mathrm{ns}}$ \\
C.V. ${ }^{(4)}$ & 9,5 & 16,2 & 20,0 & 6,1 & 13,0 \\
\hline
\end{tabular}

${ }^{1}$ fonte de variação; ${ }^{2}$ adubação verde; ${ }^{3}$ densidade do solo; ${ }^{4}$ coeficiente de variação (\%)

A ausência de efeito dos níveis de compactação resultante das diferentes intensidades de tráfego nos componentes de produção, tal como na produtividade de soja, é um indicativo de que as plantas de cobertura de solo cultivadas durante o inverno podem ter amenizado os efeitos restritivos da compactação do solo no desenvolvimento das plantas. Este resultado corrobora com os apresentados por Muller et al. (2001) que, estudando diferentes plantas de cobertura de inverno em diversos níveis de compactação, concluíram que o nabo forrageiro e a aveia preta são eficientes na melhoria dos atributos físicos do solo com compactação subsuperficial, mostrando vigor no crescimento de raízes dentro e abaixo da camada compactada do solo. Além disto, outro fato que pode ter contribuído para esta ausência de efeito dos níveis de tráfego no desenvolvimento e produtividade da soja, foi a realização da semeadura desta oleaginosa utilizando-se semeadora dotada de sulcador (regulado para trabalhar em uma profundidade de $0,07 \mathrm{~m}$ ), resultando no rompimento parcial da camada superficial (mais afetada pelos níveis de tráfego) e, sem dúvida, em condições adequadas para o desenvolvimento radicular da soja uma vez que em camadas mais profundas $(0,10-0,20$ e $0,20-0,30$ $\mathrm{m})$, não se observou efeito expressivo dos níveis de tráfego sobre os atributos físicos do solo avaliados (Figura 1A, B e C). Ao comparar a escarificação mecânica com a biológica (nabo forrageiro + aveia preta), em um Latossolo muito argiloso, Nicoloso et al. (2008) concluíram que as duas práticas beneficiaram a qualidade física do solo e aumentaram a produtividade da soja, de modo similar.

Quanto à produtividade da soja cultivada após aveia preta e nabo forrageiro, foram obtidos, respectivamente, valores médios de 3.750 e $3.540 \mathrm{~kg} \mathrm{ha}^{-1}$ (Figura 5). Esta produtividade é superior à média obtida na safra 2010 para o estado de Santa Catarina que, segundo IBGE (2011) foi de $3.060 \mathrm{~kg} \mathrm{ha}^{-1}$, fato que demonstra o adequado desenvolvimento das plantas nas condições experimentais não sendo afetadas pelo efeito da compactação nos diferentes níveis de tráfego. Beutler et al. (2006), para diferentes cultivares de soja cultivadas em Argissolo Vermelho submetido a diferentes níveis de compactação esperavam obter produtividade entre 3,5 a 4,0 $\mathrm{t} \mathrm{ha}^{-1}$; no entanto, devido à incidência de ferrugem asiática e à época tardia de semeadura, obtiveram produtividade inferior (1,2 a $\left.2,3 \mathrm{t} \mathrm{ha}^{-1}\right)$.

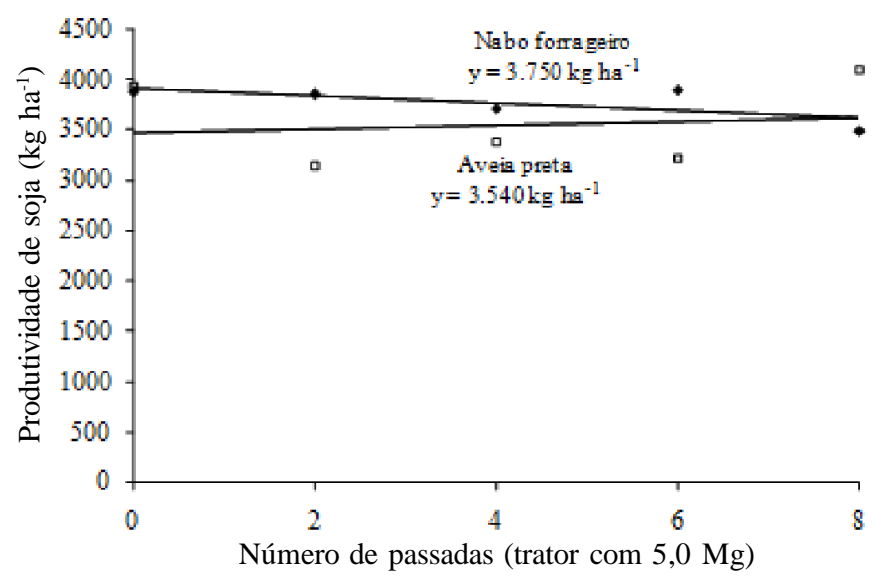

Figura 5. Produtividade da soja após o cultivo de aveia preta e nabo forrageiro em solo submetido a diferentes níveis de tráfego

\section{ConClusões}

1. Os níveis de tráfego alteram a densidade do solo, a porosidade total e a resistência do solo à penetração na camada de 0-0,10 m, mas nas camadas de 0,10-0,20 e 0,20-0,30 m de profundidade, apenas a resistência à penetração.

2. Níveis de tráfego superiores a duas passadas de trator, resultam em valores de resistência à penetração maiores que 1,4 MPa, ocasionando redução significativa na quantidade de matéria seca produzida pela parte aérea do nabo forrageiro e da aveia preta. 
3. O cultivo da aveia e do nabo forrageiro, associado ao uso do sulcador durante a semeadura da soja minimizou os efeitos da compactação do solo ocasionados pelo tráfego, possibilitando a obtenção de produtividades superiores a 3.500 $\mathrm{kg} \mathrm{ha}^{-1}$.

\section{LITERATURA CITADA}

Bergamin,A. C.; Vitorino, A. C. T.; Franchini, J. C.; Souza, C. M. A.; Souza, F. R. Compactação em um Latossolo Vermelho distroférrico e suas relações com o crescimento radicular do milho. Revista Brasileira de Ciência doSolo, v.34, p.681-691, 2010.

Beutler, A. N.; Centurion, J. F. Efeito do conteúdo de água e da compactação do solo na produção de soja. Pesquisa agropecuária Brasileira, v.38, p.849-856, 2003.

Beutler, A. N.; Centurion, J. F.; Centurion, M. A. P.; Freddi, O. S., Sousa Neto, E. L.; Leonel, C. L.; Silva, A. P. da. Traffic soil compaction of an Oxisol related to soybean development and yield. Scientia Agrícola, v.64, p.608-615, 2007.

Beutler, A. N.; Centurion, J. F.; Centurion, M. A. P.; Silva, A. P. da. Efeito da compactação na produtividade de cultivares de soja em Latossolo vermelho. Revista Brasileira de Ciência do Solo, v.30, p.787-794, 2006.

Bordin, I.; Neves, C. S. V. J.; Francio Filho, P.; Preti, E. A.; Cardoso, C. Crescimento de milheto e guandu, desempenho de plantas cítricas e propriedades físicas do solo escarificado em um pomar. Revista Brasileira de Ciência do Solo, v.32, p.1409-1418, 2008.

Braida, J. A.; Reichert, J. M.; Veiga, M.; Reinert, D. J. Resíduos vegetais na superfície e carbono orgânico do solo e suas relações com a densidade máxima obtida no ensaio de Proctor. Revista Brasileira de Ciência do Solo, v.30, p.605614, 2006.

Carvalho, G. J.; Carvalho, M. P.; Freddi, O. S.; Martins, M. V. Correlação da produtividade do feijão com a resistência à penetração do solo sob plantio direto. Revista Brasileira de Engenharia Agrícola e Ambiental, v.10, p.765-771, 2006.

Collares, G. L.; Reinert, D. J.; Reichert, J. M.; Kaiser, D. R. Compactação de um Latossolo induzida pelo tráfego de máquinas e sua relação com o crescimento e produtividade de feijão e trigo. Revista Brasileira de Ciência do Solo, v.32, p.933-942, 2008.

Dias Júnior, M. S. Compactação do solo. In: Novais, R. F.; Alvarez, V. V. H.; Schaefer, C. E. G R., (ed.) Tópicos em ciência do solo. Viçosa: Sociedade Brasileira de Ciência do Solo, v.1, p.55-94, 2000.

EMBRAPA-Empresa Brasileira de Pesquisa Agropecuária. Manual de métodos de análises de solo. 2.ed., Rio de Janeiro: Centro Nacional de Pesquisa de Solos, Embrapa Solos, 1997. 212p.

EPAGRI - Empresa de Pesquisa Agropecuária e Extensão Rural de Santa Catarina. Recomendação de cultivares para o estado de Santa Catarina. Florianópolis: EPAGRI, 1993. 118p.

Forsthofer, E. L.; Silva, P. R. F.; Strieder, M. L.; Minetto, T.; Rambo, L.; Argenta, G.; Sangoy, L.; Suhre, E.; Silva, A. A. Desempenho agronômico e econômico do milho em diferentes níveis de manejo e épocas de semeadura. Pesquisa Agropecuária Brasileira, v.41, p.399-407, 2006.
Freddi, O. S.; Centurion, J. F.; Beutler, A. N.; Aratani, R. G.; Leonel, C. L. Compactação do solo no crescimento radicular e produtividade da cultura do milho. Revista Brasileira de Ciência do Solo, v.31, p.627-636, 2007.

Guimarães, C. M.; Stone, L. F.; Moreira, A. A. Compactação do solo na cultura do feijoeiro. II: Efeito sobre o desenvolvimento radicular e da parte aérea. Revista Brasileira de Engenharia Agrícola e Ambiental, v.6, p.213-218, 2002.

IBGE - Instituto Brasileiro de Geografia e Estatística. http:// www.ibge.gov.br/home/ estatistica/economia/agropecuaria/ censoagro. 08 Ago. 2011.

Jimenez, R. L.; Gonçalves, W. G.; Araújo Filho, J. V.; Assis, R. L.; Pires, F. R.; Silva, G. P. Crescimento de plantas de cobertura sob diferentes níveis de compactação em um Latossolo Vermelho. Revista Brasileira de Engenharia Agrícola e Ambiental, v.12, p.116-121, 2008.

Müller, M. M. L.; Ceccon, G.; Rosolem, C. A. Influência da compactação do solo em subsuperfície sobre o crescimento radicular de plantas de adubação verde de inverno. Revista Brasileira de Ciência do Solo, v.25, p.531-538, 2001.

Nicoloso, R. S.; Amado, T. J. C.; Schneider, S.; Lanzanova, M. E.; Girardello, V. C.; Bragagnolo, J. Eficiência da escarificação mecânica e biológica na melhoria dos atributos físicos de um Latossolo muito argiloso e no incremento do rendimento de soja. Revista Brasileira de Ciência do Solo, v.32, p.17231734, 2008.

Ralisch; R.; Miranda, T. M.; Okumura, R. S.; Barbosa, G. M. C.; Guimarães, M. F.; Scopel, E.; Balbino, E. C. Resistência à penetração de um Latossolo Vermelho Amarelo do Cerrado sob diferentes sistemas de manejo. Revista Brasileira de Engenharia Agrícola e Ambiental, v.12, p.381-384, 2008.

Ribeiro, M. A. V.; Novais, R. N.; Faquin, V.; Ferreira, M. M.; Furtini Neto, A. E.; Lima, J. M. de; Villani, E. M. A. Resposta da soja e do eucalipto ao aumento da densidade do solo e a doses de fósforo. Revista Brasileira de Ciência do Solo, v.34, p.1157-1164, 2010.

Ros, C. O. da; Secco, D.; Fiorin, G. W. Manejo do solo a partir de campo nativo: efeito sobre a estabilidade da estrutura ao final de cinco anos. Revista Brasileira de Ciência do Solo, v.21, p.241-247, 1997.

Rosolem, C. A.; Almeida, A. C. S.; Sacramento, L. V. S. Sistema radicular e nutrição da soja em função da compactação do solo. Bragantia, v.53, p.259-266, 1994a.

Rosolem, C. A.: Vale, L. S. R.; Grassi Filho, H.; Moraes, M. H. Sistema radicular e nutrição do milho em função da calagem e da compactação do solo. Revista Brasileira de Ciência do Solo, v.18, p.491-497, 1994b.

SAS Institute. Getting started with the SAS Learning Edition, Care, North Carolina: SAS Institute Inc. 2002. 200p.

Silva, A. A.; Paulo Silva, P. R. F.; Suhre, E.; Argenta, G.; Strieder, M. L.; Rambo, L. Sistemas de coberturas de solo no inverno e seus efeitos sobre o rendimento de grãos do milho em sucessão. Ciência Rural, v.37, p.928-935, 2007.

Silva, G. J.; Maia, J. C. S; Bianchini, A. Crescimento da parte aérea de plantas cultivadas em vaso, submetidas à irrigação subsuperficial e a diferentes graus de compactação de um Latossolo Vermelho-escuro distrófico. Revista Brasileira de Ciência do Solo, v.30, p.31-40, 2006. 
Smith, C. W.; Johnston, M. A.; Lorentz, S. The effect of soil compaction and soil physical properties on the mechanical resistance of South African forestry soils. Geoderma, v.78, p.93-111, 1997.

Soane, B. D.; Ouwerkerk, C. van. Soil compaction in crop production. In: Soane, B. D.; Van Ouwerkerk, C. (ed.). Soil compaction problems in world agriculture. Amsterdam: Elsevier, p.1-21, 1994.
Tavares Filho, J.; Ralisch, R.; Guimarães, M. F.; Medina, C. C.; Balbino, L. C.; Neves, C. S. V. J. Método do perfil cultural para avaliação do estado físico de solos em condições tropicais. Revista Brasileira de Ciência do Solo, v.23, p.393-399, 1999.

Tormena, C. A.; Silva, A. P.; Libardi, P. L. Caracterização do intervalo hídrico ótimo de um Latossolo Roxo sob plantio direto. Revista Brasileira de Ciência do Solo, v.22, p.573581, 1998. 